\title{
A Comparative Study on the Efficiency of Online Learning Management Platform for Telecommunications Store Retail Employees in 2020
}

\author{
Hazel Joy Nacino ${ }^{1}$, Ma. Christiana Mae L. Ilagan², Sienna Marie V. Evangelista ${ }^{3}$, Venus \\ S. Vallejos ${ }^{4}$, FerleneS. Olpindo ${ }^{5}$, Jennifer G. Fronda ${ }^{6}$
}

\author{
${ }^{1}$ Boltech Device Protection Asia Inc \\ ${ }^{2}$ Self-employed \\ ${ }^{3}$ Department of Education- Carranglan National High School \\ ${ }^{4}$ Department of Environment and National Resources \\ ${ }^{5}$ Department of Education- Agbannawag National High School \\ ${ }^{6}$ Graduate School, Nueva Ecija University of Science and Technology, Philippines
}

Received: 02 May 2021; Received in revised form: 29 May 2021; Accepted: 11 Jun 2021; Available online: 20 Jun 2021 (C)2021 The Author(s). Published by Infogain Publication. This is an open access article under the CC BY license (https://creativecommons.org/licenses/by/4.0/).

\begin{abstract}
This research studied the efficiency of the Online Learning Management Platform for telecommunication (Telco) retail employees. The researchers conducted online surveys and interviews with 36 senior managers and trainers that have experience on both traditional and online learning platforms. The researchers found out that costs, manpower, and learning retention are the factors that need to be considered in the efficacy of online learning systems in training and seminars for continuous improvement of skills. Telco retail employees deal directly with customers, it is very important that they receive adequate training on how to provide great customer service and increase sales. This paper concludes that the adoption of online LMS of companies requires trainers to upgrade their training skills and knowledge. The findings and conclusions are relevant in the present time.
\end{abstract}

Keywords- Efficiency, learning retention, online learning management platform, senior managers, telecommunication (Telco) retail employees.

\section{INTRODUCTION}

The continuous and fast technological development, continuous training, and development of sales employees among telecommunication retail companies had been a very important component in achieving the company's goal in terms of sales production, and market positioning. It is also very necessary for the young demographic of employees who are accustomed to having their individualized needed information readily available on their phones because this helps them to be continuously updated with the latest technological updates as well as have their skills developed to stay competitive [1].

The Philippines is composed of 7107 islands, and all throughout, these islands are different Telco Retail company players. Some of the biggest players are Fonestyle with over 236 stores, MemoXpress with 251 stores, and BSD Telecom with 186 stores nationwide. All of which along with other 31 more retailers, Telco Consumer Financing companies, phone manufacturers, and device protection providers are partnered with these Telco retail companies [2].

Conducting training for the sales employees on a regular basis had been inefficient and costly because of this setup. Gathering them would mean time away from their sales post that greatly affects sales and incurs a lot of expenses. These include transportation, venue, accommodation, per diem, etc. Moreover, traditional classroom training does not guarantee $100 \%$ effectiveness [3]. 
In 1956, George Miller introduced the magical number $7 \pm 2$. According to this psychological principle, working memory can only process seven chunks of information at any given time, plus or minus two items. Once a learning task exceeds these cognitive limits, our ability to process and retain information diminishes[4].

On the other hand, the latest accounting reports for the $3 \mathrm{rd}$ quarter of 2019, on average, the monthly training cost of Amtrust mobile solutions eats up at least $34 \%$ of the monthly Sales budget [5]. This represents monthly spending of 150,000 pesos or 1,800,000 pesos per year. Compared to using an E-learning portal proposed by Nephila Web called "Moodle" the company can eliminate at least $68 \%$ of its yearly cost. The company will be greatly benefited from these savings. The $68 \%$ estimated yearly savings can be re-directed for employee motivational programs [5]. This also means employees will get a more focused learning material based on their individual needs, therefore becoming more effective. Adopting a new and more effective training tool is crucial for the company's continued competitiveness and financial health.

\section{METHODOLOGY}

This study made use of a qualitative research strategy. where the research approach implemented has been that of interpretivism. An approach that is implemented by the researchers in order to synthesize facts that are derived mainly from secondary sources, and which are qualitative in nature[6]. The study will attempt to show how the efficiency of Online learning in terms of cost, manpower, and learner's level of knowledge retention, and learner's output in terms of sales. The results of the analysis would be than being the basis in proposing a strategic alternative for a company's training team[7]. The study was conducted all throughout the Philippines, to Managers/ Senior trainers of two Consumer loan companies, Device protection, and a Mobile Phone Manufacturer station in different regions in the Philippines. The study used two sets of questionnaires, in gathering the data. An unstructured interview was also conducted to elicit additional information and to check the consistency of responses. The questionnaire for trainers harbored on the transition types on online learning being used and how it is being utilized, factors considered in online training (cost, manpower, learning retention), and outcome results of the learners. To compare and ensure the clarity of direction, only Senior trainers/managers with traditional training experience were selected as respondents.

III. RESULTS AND DISCUSSION

\section{A. Profile of the Respondent}

Table 2.1 Demographic Profile

\begin{tabular}{lccccccc}
\hline $\begin{array}{l}\text { Managers/Senior } \\
\text { Trainers }\end{array}$ & & Age & & Gender & \multicolumn{2}{c}{$\begin{array}{c}\text { Highest Educational } \\
\text { Attainment }\end{array}$} \\
\hline & $20-30$ & $30-40$ & $40-50$ & Male & Female & $\begin{array}{c}\text { Bachelor's } \\
\text { degree }\end{array}$ & Masters \\
Number of & 17 & 18 & 1 & 21 & 15 & 26 & 10 \\
$\begin{array}{l}\text { respondents } \\
\text { Percentage }\end{array}$ & $47 \%$ & $50 \%$ & $3 \%$ & $58 \%$ & $42 \%$ & $72 \%$ & $28 \%$ \\
\hline Total & & $36=100 \%$ & & $36=100 \%$ & $36=100 \%$ \\
\hline
\end{tabular}

Table 2.1 showed the demographics of the Manager/ Senior trainers. The table indicated that most of the Manager/Senior trainers are between 20-40 years old which means that they are in the age bracket of Gen $\mathrm{Z}$, Gen X, and Gen Yor millennial learners [8]. This supports the recent study conducted by Pew Research Center that Millennials (those who are 23-38 years old) stand out for their technology use but Gen Xers (38-45) also embraces technology well [2]. The higher number of Male trainers $(58 \%)$ also manifested the higher trust in men especially in more Senior positions when it comes to technology-based knowledge. "Research shows that, in general, women are more interested in people compared with men, who are more interested in things. To the extent that tech occupations are concerned more with things than people, men would on average be more attracted to them" [1].It is also noticeable that though respondents are already in a senior position, the number of Bachelor's degree graduates $(72 \%)$ is still higher than those with a post-graduate diploma. This suggested that private enterprise is more incline to look at the skills and capabilities of their employees. 


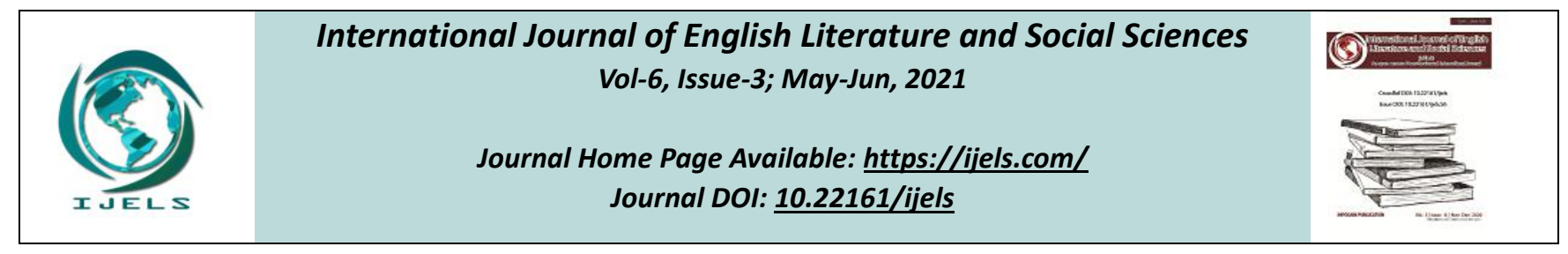

Peer-Reviewed Journal

Table 2.2 Years of Experience in Training

\begin{tabular}{ccc}
\hline Years of Experience & Frequency & Percentage \\
\hline 1-3 years & 2 & $6 \%$ \\
4-6 years & 13 & $36 \%$ \\
6-9 years & 9 & $25 \%$ \\
More than 10 years & 12 & $33 \%$ \\
\hline Total & $\mathbf{3 6}$ & $\mathbf{1 0 0 . 0 0 \%}$ \\
\hline
\end{tabular}

Table 2.2 exhibited the respondent's number of working years in Training. It is noted that $36 \%$ of the respondents have at least 4-6 years of working experience. Which is very understandable because of their age group.

Table 2.3 Experience in Using an LMS Platform

\begin{tabular}{ccc}
\hline Length of Experience & Frequency & Percentage \\
\hline 0-6 months & 9 & $25 \%$ \\
7 months -11 months & 6 & $17 \%$ \\
$1-2$ years & 11 & $31 \%$ \\
More than 2 years & 10 & $28 \%$ \\
Total & $\mathbf{3 6}$ & $\mathbf{1 0 0 . 0 0 \%}$ \\
\hline
\end{tabular}

Established from the data gathered, most of the respondents have been using an online LMS for at least a year, that's $31 \%$ of the total respondents. It was also remarkable that $42 \%$ of the total respondents are new users ( $0-11$ months). Compared to the respondent's average years of training experience the table also showed that most of the respondents have been using other or traditional training styles prior to their use of the online platform.

\section{B. Challenges Encountered in Traditional Training Style}

Table 3 Challenges Manager/Senior Trainers encountered

\begin{tabular}{llrr}
\hline \multicolumn{1}{c}{ Variables } & \multicolumn{1}{c}{ Category } & Frequency & Percentage \\
\hline \multirow{2}{*}{ Training cost } & Meals Expense & 11 & $31 \%$ \\
& Venue and Accommodation Expense & 7 & $19 \%$ \\
Total & Travel Expense & 18 & $\mathbf{1 0 0 \%}$ \\
& & & $30 \%$ \\
Manpower & Lack of manpower/trainer in the area & 1 & $3 \%$ \\
Requirement & Individual productivity in a month & 31 & $\mathbf{1 0 0}$ \\
& & 4 & $\mathbf{1 0 0 \%}$ \\
Total & A fair measure of trainer's performance & & $3 \%$ \\
Learning retention & Learner's pass rate & 1 & $72 \%$
\end{tabular}


Application of learnings 9 $25 \%$

It can be learned from table 3 that the biggest cost contributor in Training cost is Travel expense (50\%). This includes airfare, gas, toll fees, and Ferry tickets both for the trainers and trainees. This is followed by Meals expenses $31 \%$ then Venue and accommodation rental at $19 \%$. Even though only $3 \%$ ( 1 respondent) answered that lack of manpower/trainer in the area is the challenge, the number 1 challenge identified when it comes to manpower requirement is the low productivity rate of each trainer. According to an interview with one of the National Training Managers, on average trainer can only conduct nine training sessions per month or a total of 180 trainees'. That is just $7.2 \%$ of the reach target every month.Finally, in terms of learning retention, it was also identified in table 3 that the biggest challenge is the lack of accurate measures when it comes to learning retention. Traditional trainers would usually use printer handouts and quizzes to measure the trainee's understanding right after the lesson was given. But to how much of the learning was retained after, there was no visibility.

\section{Comparison of 2 Training method}

Table 4 Comparison of Traditional learning and Online LMS

\begin{tabular}{|c|c|c|c|c|c|c|c|c|c|}
\hline \multirow{2}{*}{ Variables } & \multirow{2}{*}{ Category } & \multicolumn{2}{|c|}{ Increased } & \multicolumn{2}{|c|}{ Decreased } & \multicolumn{2}{|c|}{ Maintained } & \multirow{2}{*}{ Total (F) } & \multirow[t]{2}{*}{ Total (\%) } \\
\hline & & Frequency & Percentage & Frequency & Percentage & Frequency & Percentage & & \\
\hline \multirow{3}{*}{ Training cost } & Meals Expense & 0 & $0 \%$ & 36 & $100 \%$ & 0 & $0 \%$ & 36 & $100 \%$ \\
\hline & Venue and Accomodation expense & 0 & $0 \%$ & 36 & $100 \%$ & 0 & $0 \%$ & 36 & $100 \%$ \\
\hline & Travel Expense & 0 & $0 \%$ & 36 & $100 \%$ & 0 & $0 \%$ & 36 & $100 \%$ \\
\hline \multirow{3}{*}{ Manpower Requirement } & Lack of manpower/trainer in the area & 7 & $19 \%$ & 18 & $50 \%$ & 11 & $31 \%$ & 36 & $100 \%$ \\
\hline & Individual productivity in a month & 29 & $81 \%$ & 3 & $8 \%$ & 4 & $11 \%$ & 36 & $100 \%$ \\
\hline & Fair meassure of trainer's performance & 28 & $78 \%$ & 2 & $6 \%$ & 6 & $17 \%$ & 36 & $100 \%$ \\
\hline \multirow{3}{*}{ Learning retention } & Learner's pass rate & 15 & $42 \%$ & 9 & $25 \%$ & 12 & $33 \%$ & 36 & $100 \%$ \\
\hline & Meassure on learning retention & 32 & $89 \%$ & 0 & $0 \%$ & 4 & $11 \%$ & 36 & $100 \%$ \\
\hline & Application of learnings & 3 & $8 \%$ & 0 & $0 \%$ & 33 & $92 \%$ & 36 & $100 \%$ \\
\hline
\end{tabular}

Gathered in Table 4 are the changes (if any) that happened after the company adopted an online LMS. It is very remarkable that the use of LMS completely zeroed out the usual training cost that is usually incurred on a traditional training method.Though the majority of the respondents $(50 \%)$ said that they had a decrease in their headcount challenge, it was observed that those respondents who had a challenge on their manpower increased (19\%). This is compared to table 3 where only 1 respondent identified this as their major challenge. Individual productivity was also so as the fair measure of the trainer's performance.Most of the respondents also indicated that their learner's pass rate was also increased(42\%) though it is also noted that $33 \%$ of said that it was just maintained or not improved. The measure of learning retention was significantly increased $(89 \%)$ mainly because one of the key features of online learning is its ability to induce learning to the learners any time of the day, therefore accurately measuring them retain knowledge. In terms of knowledge application, most respondents indicated that it was maintained mainly because the measure being used is the same.

\section{CONCLUSIONS AND RECOMMENDATIONS}

Based on the data presented the researchers, therefore, conclude that:

1. Most employees find it easy to adopt an online learning system [9] because they tend to be more inclined toward technology.

2. Learning management systems offer companies a more cost-efficient way of delivering continuous learning to employees.

3. The adoption of online LMS of companies requires trainers to upgrade their training skills and knowledge.

4. Online LMS can deliver almost the same because of the constant availability of knowledge to its user but it still cannot replace the face-to-face interaction and encouragement that a traditional training method offers. 
Considering the data and conclusion made, the researchers, therefore, recommend the following:

1. The use of an online learning management platformand the developed framework [10] system must be adapted as a way to deliver a high-quality training experience while being cost-efficient.

2. Blended learning may also be done to ensure efficiency and effectiveness.

3. As more and more companies are embracing online learning options, trainers must continuously and openly adopt and learn new skills in order to cope up with the changing job requirements.

4. A faster, higher, and stable internet bandwidth must be secured to ensure that online seminars or training are not interrupted due to technical problems.

5.The company may outsource a more experience online manager trainer to achieve optimum results.

\section{REFERENCES}

[1] Vogels, E., (September 2019) Research Associate. Millennials Technology Use. https://www.pewresearch.org/fact-tank/2019/09/09/usgenerations-technology-use/

[2] https://www.statista.com/topics/5678/telecommunicationindustry-in-the-philippines/

[3] Lambda Solutions (December 2019). E-Learning vs Classroom: LMS Cost Comparison and Benefits. https://www.lambdasolutions.net/blog/lms-costcomparison-and-benefits-elearning-vs-classroom

[4] Freifeld, L., (November 2019), 2019 Training Industry Report. https://trainingmag.com/2019-training-industryreport/

[5] https://nephilaweb.com.ph/

[6] Scauso. Marco (February 2020). Interpretivism: Definitions, Trends, and Emerging Paths. https://doi.org/10.1093/acrefore/9780190846626.013.522

[7] Anderson, T., \&Dron, J. (2011). Three generations of distance education pedagogy. The International Review of Research in Open and Distributed Learning, 12(3), 80-97. doi:10.19173/irrodl. v12i3.890 [Crossref], [Web of Science (B]

[8] Subia, Gener S. Think Like My Teacher (TLMT): A New Method in Assessing Millennial Learners. International Journal of Arts, Humanities and Social Sciences.Volume 3. Issue 1.2018. 57-61.www.ijahss.com

[9] Mina, J., Subia, G., Pascuala, P., Tuliao, R. \&Pastorfide,D.(2020). Inclinations of Engineering and Marketing Management Students to Engage in Online Learning Technology Amidst the COVID-19 Pandemic. Technology Reports of Kansai University. ISSN: 04532198 Volume 62, Issue 09, October 2020.

[10] Russell N. Alfonso, Marlon C. Leyesa, Donald M. Lapiguera, Noel Florencondia, Gener S.Subia. Proposed
Design for Framework Management of Cryptocurrency: Study of the World's First Digital Currency International Journal of Engineering Trends and Technology, 68(1),5763. 